\title{
Hepatocyte specific expression of an oncogenic variant of $\beta$-catenin results in cholestatic liver disease
}

\author{
Ursula J. Lemberger ${ }^{1,2,3}$, Claudia D. Fuchs ${ }^{3}$, Matthias Karer ${ }^{1}$, Stefanie Haas ${ }^{1}$, Tatjana \\ Stojakovic ${ }^{4}$, Christian Schöfer ${ }^{5}$, Hanns-Ulrich Marschall6, Fritz Wrba², Makoto M. \\ Taketo7, Gerda Egger ${ }^{2}$, Michael Trauner ${ }^{3}$, Christoph H. Österreicher ${ }^{1}$ \\ ${ }^{1}$ Institute of Pharmacology, Medical University of Vienna, Vienna, Austria \\ ${ }^{2}$ Clinical Institute of Pathology, Medical University of Vienna, Vienna, Austria \\ ${ }^{3}$ Hans Popper Laboratory for Molecular Hepatology, Department of Internal Medicine, Medical University of Vienna, Vienna, Austria \\ ${ }^{4}$ Clinical Institute of Medical and Chemical Laboratory Diagnostics, Medical University of Graz, Graz, Austria \\ ${ }^{5}$ Department of Cell and Developmental Biology, Medical University of Vienna, Vienna, Austria \\ ${ }^{6}$ Department of Molecular and Clinical Medicine, Sahlgrenska Academy, University of Gothenburg, Gothenburg, Sweden \\ ${ }^{7}$ Division of Experimental Therapeutics, Graduate School of Medicine, Kyoto University, Kyoto, Japan
}

Correspondence to: Christoph H. Österreicher, email: coesterr@gmail.com

Keywords: $\beta$-catenin, bile acids, cholestasis, biliary fibrosis, liver cancer

Received: April 03, 2016 Accepted: September 26, $2016 \quad$ Published: November 23, 2016

Copyright: @ 2021 Lemberger et al. This is an open access article distributed under the terms of the Creative Commons Attribution License (CC BY 3.0), which permits unrestricted use, distribution, and reproduction in any medium, provided the original author and source are credited.

\section{ABSTRACT}

Background: The Wnt/ $\beta$-catenin signaling pathway plays a crucial role in embryonic development, tissue homeostasis, wound healing and malignant transformation in different organs including the liver. The consequences of continuous $\beta$-catenin signaling in hepatocytes remain elusive.

Results: Livers of Ctnnb1cA hep mice were characterized by disturbed liver architecture, proliferating cholangiocytes and biliary type of fibrosis. Serum ALT and bile acid levels were significantly increased in Ctnnb1 ${ }^{\text {ca hep }}$ mice. The primary bile acid synthesis enzyme Cyp7a1 was increased whereas Cyp27 and Cyp8b1 were reduced in Ctnnb1 ${ }^{\text {CA }}$ hep mice. Expression of compensatory bile acid transporters including $A b c b 1$, $A b c b 4, A b c c 2$ and $A b c c 4$ were significantly increased in Ctnnb1 ${ }^{\text {CA hep }}$ mice while Ntcp was reduced. Accompanying changes of bile acid transporters favoring excretion of bile acids were observed in intestine and kidneys of Ctnnb1 ${ }^{\text {CA hep }}$ mice. Additionally, disturbed bile acid regulation through the FXR-FGF15-FGFR4 pathway was observed in mice with activated $\beta$-catenin.

Materials and Methods: Mice with a loxP-flanked exon 3 of the Ctnnb1 gene were crossed to Albumin-Cre mice to obtain mice with hepatocyte-specific expression of a dominant stable form of $\beta$-catenin (Ctnnb1 ${ }^{\text {CA hep }}$ mice). Ctnnb1 ${ }^{\text {CA hep }}$ mice were analyzed by histology, serum biochemistry and mRNA profiling.

Conclusions: Expression of a dominant stable form of $\beta$-catenin in hepatocytes results in severe cholestasis and biliary type fibrosis.

\section{INTRODUCTION}

The Wnt/ $\beta$-catenin signaling pathway is an evolutionary preserved system, which plays a crucial role in embryonic development, tissue homeostasis, wound healing and malignant transformation in different organs including the liver [1-3]. $\beta$-catenin forms a cytoplasmatic complex with axin, adenomatous polyposis coli (APC) and glycogen synthase kinase- $3 \beta$ (GSK-3 $\beta$ ) and is the key mediator of the canonical Wnt signaling pathway. In the absence of Wnt stimulation, GSK-3 $\beta$ is active and phosphorylates different serine and threonine residues (S33, S37, T41 and S45) within exon 3 of the Ctnnb1 gene, leading to proteasomal degradation of $\beta$-catenin. Canonical Wnt signaling results in inactivation of GSK-3 $\beta$ and accordingly leads to inhibition of ubiquitin-mediated 
degradation of $\beta$-catenin. This leads to cytoplasmic accumulation and subsequent nuclear translocation of $\beta$-catenin, where it replaces Groucho from T-cell factors (TCFs). $\beta$-catenin then forms a transcriptional activation complex following recruitment of transcriptional coactivators and histone modifiers and induces expression of cyclinD1, c-myc, glutamine synthetase and other target genes [1].

Genetic deletion of $\beta$-catenin in mice results in $100 \%$ lethality at embryonic day E9.5 due to defects in anteriorposterior development [4]. The subsequent generation of mice with a conditional allele of $\beta$-catenin has allowed investigating the role of $\beta$-catenin in a cell type specific manner [5]. Mice with hepatocyte-specific deletion of $\beta$-catenin $\left(C t n n b 1^{\text {thep }}\right)$ have significantly improved our understanding of the role of $\beta$-catenin in liver biology and liver disease. In this respect, it was demonstrated that $\beta$-catenin is temporally regulated during normal liver development and controls hepatic morphogenesis and zonation of the liver [6-10]. Hepatocyte-specific deletion of $\beta$-catenin results in bile canalicular abnormalities, bile secretory defects and intrahepatic cholestasis [11]. Bile acid synthesis largely depends on the first and rateliming enzyme CYP7A1 and is regulated by feedback mechanisms involving the Farnesoid $\mathrm{X}$ receptor (FXR) [12]. A complex network of transcription factors, bile acid forming and modifying enzymes and bile acid transporters and regulates formation and secretion of bile acids into the small intestine, their re-absorption and transport to the liver or their excretion via feces and urine. These include members of the ATP-binding cassette (ABC) transporter family such as $\mathrm{ABCB} 11$, the main transporter for bile acids in hepatocytes. Additionally, there are compensatory transporters such as $\mathrm{ABCC} 2$ and $\mathrm{ABCB} 1$. Hepatocytes are also equipped with transporters at their basolateral membrane, which allows them to shuttle bile acids into the blood of the systemic circulation via $\mathrm{ABCC} 4$ enabling renal clearance [13]. Morevoer, the $\mathrm{Na}+$ co-transporter polypeptide (NTCP) mediates the re-uptake of bile acids reaching the liver from enterohepatic circulation [12].

Furthermore, $C$ tnnb $1^{\text {thep }}$ mice also display delayed liver regeneration following partial hepatectomy and are susceptible to the development of steatohepatitis in response to metabolic stress (MCD diet) and alcohol [9, 14-18]. In contrast, Ctnnb $1^{\text {thep }}$ mice are protected from acetaminophen induced hepatotoxicity due to lack of CYP2E1 expression, a key enzyme in the metabolism of acetaminophen and responsible for the formation of the toxic metabolite $\mathrm{N}$-acetyl-p-benzoquinone imine which causes hepatocyte necrosis [19].

Somatic mutations of the $\beta$-catenin gene are frequent in mouse and human hepatocellular carcinomas (HCC) [20-25]. In a recent study it was demonstrated that the $\mathrm{Wnt} / \beta$-catenin pathway is the most frequently altered signaling pathway in patients with HCC [26]. Somatic mutations in CTNNB1 were observed in $32.8 \%$ of patients typically affecting serine and threonine residues encoded by exon 3 of the $C T N N B 1$ gene. Furthermore, inactivating mutations in AXIN1 and APC leading to activation of $\beta$-catenin were reported in $15.2 \%$ and $1.6 \%$ of patients respectively [27].

These findings suggest that mutations occurring in genes involved in the $\mathrm{Wnt} / \beta$-catenin signaling pathway affect $\sim 50 \%$ of patients with HCC. It was also reported that $\mathrm{HCC}$ harboring somatic missense mutations in exon 3 of $C T N N B 1$ exhibit a histologically more aggressive phenotype [24]. However, adenovirus-mediated expression of a dominant stable mutant of $\beta$-catenin does not result in tumorigenesis in mice suggesting that continuous $\beta$-catenin signaling alone is not sufficient for malignant transformation of hepatocytes [28]. The same laboratory later demonstrated that $\beta$-catenin cooperates with Ha-Ras in hepatocarcinogenesis in mice [29]. Mice expressing a serine- 45 mutant, non-degradable form of $\beta$-catenin display accelerated hepatocarcinogenesis in response to diethylnitrosamine (DEN) treatment [15]. However, conditional loss of $\beta$-catenin in mice also promotes chemical hepatocarcinogenesis due to impaired handling of oxidative stress in response to DEN treatment [30].

Whereas Ctnnb $1^{\text {thep }}$ mice have significantly improved our understanding on the role of $\beta$-catenin in liver biology they do not mimic human liver disease. A significant proportion of human HCCs are characterized by somatic mutations in CTNNB1 associated with continuous $\beta$-catenin signaling rather than loss of function.

In the present study we addressed the consequences of continuous $\beta$-catenin signaling in hepatocytes on liver biology.

\section{RESULTS}

\section{Continuous $\beta$-catenin signaling leads to liver injury, bile duct proliferation and biliary type fibrosis}

Hepatocyte specific expression of a dominant stable form of $\beta$-catenin was accomplished by crossing Albumin-Cre mice in which Cre recombinase is driven by the mouse Albumin enhancer/promoter to mice in which exon 3 of the Ctnnbl gene is flanked by loxP sequences, further referred to as $C t n n b 1^{C A}$ hep . Mice were born at the expected Mendelian ratio (Cre positive: $53.1 \%$ ) and no differences with respect to sex distribution were observed. The expression of the truncated form of $\beta$-catenin was confirmed by immunoblotting of whole liver tissue of Ctnnb1 $1^{\text {CA hep }}$ mice and healthy littermates (Figure 1A). Glutamine synthetase (Glul) mRNA levels were 8-fold increased and Cyclin D1 (Ccnd1) mRNA showed a mild trend towards upregulation in Ctnnb $1^{\text {CA hep }}$ mice compared to Cre-negative controls indicating continuous $\beta$-catenin signaling and transcription of $\beta$-catenin target genes (Figure 1A). To investigate putative early phenotypic 
consequences of continuous $\beta$-catenin activation we analyzed mice at the age of 21 days upon weaning. Livers of Ctnnb1 ${ }^{C A}$ hep mice showed a disturbed liver architecture. Intriguingly no signs of tumor formation could be observed (Figure 1B). Ki67 staining revealed no alterations in proliferation of liver cells (Supplementary Figure S1A), however a slight increase in apoptosis of cholangiocytes was observed in livers of Ctnnb1 ${ }^{\text {CA hep }}$ mice as analyzed by cleaved caspase 3 staining (Supplementary Figure S1B). Serum alanine aminotransferase (ALT) levels and aspartate aminotransferase (AST) were significantly increased in Ctnnb1 $^{\text {CA hep }}$ mice (ALT: 344.4 vs. 59.6 IU/L, AST: 194.3 vs. 404.8 IU/L, $p<0.001$, Figure 1C). However, no changes in bilirubin levels could be detected (Supplementary Figure S1C).

Immunofluorescence staining for the cholangiocyte marker Keratin 19 indicated increased numbers of cholangiocytes in $C t n n b 1^{C A}$ hep mice, which was confirmed by quantitation of the Keratin 19 positive areas in Ctnnb1 ${ }^{\text {CA hep }}$ versus wild type mice $(4.8 \%$ vs. $1.1 \%$, $p<0.05$, Figure 1D and 1E). Evaluation of H\&E stained sections confirmed these findings (Supplementary Figure S1D). Moreover, a dedifferentiation of hepatocytes in $C$ tnnb1 ${ }^{\text {CA hep }}$ mice was observed by immunofluorescence double staining, where some HNF4 positive hepatocytes also express Keratin 19 (Supplementary Figure S1E). "Reactive" cholangiocytes as observed in Ctnnb1 ${ }^{\text {CA hep }}$ mice are a hallmark of cholestatic liver injury. In this respect, cholestasis can lead to scarring as a consequence of a chronic wound-healing response. Accordingly, we observed a biliary type of fibrosis in Ctnnb1 ${ }^{\text {CA hep }}$ mice (Figure 1F). Morphometric quantification of Sirius red stained sections indicated significantly increased collagen deposition in $\mathrm{Ctnnb1}^{\text {CA hep }}$ mice compared to Cre-negative controls (3.82 vs. $0.98 \%, p<0.001$; Figure $1 \mathrm{G}$ ), which was also confirmed by quantification of hepatic hydroxyproline levels (77.6 vs. 173,7 $\mu \mathrm{g}$ OH-proline/mg liver; Figure 1H). In line with these results, immunofluorescence staining for desmin revealed increased numbers of hepatic stellate cells in Ctnnb1 ${ }^{\text {CA hep }}$ mice in the portal tracts surrounding proliferating cholangiocytes suggesting hepatic stellate cells as the major source of activated myofibroblasts (5.93 vs. 2.08\%, $p<0.0001$; Supplementary Figure S1G). Thus, our findings indicate a chronic cholestatic liver injury with a biliary type of fibrosis and dedifferentiation of hepatocytes into cholangiocytes.

\section{Ctnnb1 $1^{\text {CA hep }}$ mice are characterized by severe cholestasis and qualitative changes in bile acid composition due to deregulation of enzymes involved in bile acid synthesis}

Electron microscopy revealed enlarged and dilated bile canaliculi in $C t n n b 1^{C A}$ hep mice (Supplementary Figure S2A). Remarkably, serum bile acid levels were $\sim 25$-fold increased in $C t n n b 1^{C A}$ hep mice compared to controls (243.8 vs. $10.5 \mu \mathrm{mol} / \mathrm{L}, p<0.0001$; Figure 2A). Furthermore, bile acid levels were also significantly increased in livers of Ctnnb1 ${ }^{\text {CA hep }}$ mice compared to Crenegative controls (1951.8 vs. $340.7 \mathrm{pmol} / \mathrm{mg}$ liver tissue, $p<0.01$; Figure 2B). Next, we evaluated expression of Cytochrome P450 key enzymes involved in bile acid synthesis by qPCR to address if increased bile acid levels in $C$ tnnb1 ${ }^{C A}$ hep mice are the consequence of increased synthesis in hepatocytes. Expression of Cyp $7 a 1$, the first and rate-limiting enzyme of the classical pathway, was significantly increased in Ctnnb1 ${ }^{\text {CA hep }}$ mice (Figure 2C). In contrast, mRNA levels of Cyp27 and Cyp8b1, key enzymes of the alternative pathway of bile acid synthesis, were significantly reduced in $C$ tnnb $1^{C A}$ hep mice (Figure 2D and 2E). Furthermore, Cyp2b10, which is a key enzyme in detoxification, was completely abolished in Ctnnb1 $1^{\text {CA hep }}$ (Supplementary Figure S2B). These results indicate that increased serum and tissue levels of bile acids in Ctnnb1 ${ }^{C A}$ hep mice result from activation of the classical pathway of bile acid synthesis.

Next we quantified individual bile acids in liver tissue of Ctnnb1 $1^{C A}$ hep mice and Cre-negative littermate controls to assess if differential expression of various CYPs involved in bile acid homeostasis translates into changes of bile acid composition. As absolute amounts of different bile acids were significantly increased in Ctnnb1 ${ }^{\text {CA hep }}$ mice, we analyzed the relative contribution of individual sterol intermediates to the total hepatic bile acid pool (Figure $2 \mathrm{~F}$ ). The percentage of tauro- $\beta$-muricholic acid ( $\beta$-TMCA) and $\beta$-muricholic acid ( $\beta$-MCA) was significantly increased in $C$ tnnb1 $1^{\text {CA hep }}$ mice compared to Cre-negative controls ( $\beta$-TMCA: $76.22 \%$ vs. $58.25 \%$, $p<0.01$; $\beta$-MCA: $4.75 \%$ vs. $0.61 \%, p<0.05$; Figure $2 \mathrm{G}$ and $2 \mathrm{H}$ ). In contrast, taurine-conjugated cholic acid (TCA) and deoxycholic acid (TDCA) were relatively decreased in livers of Ctnnb1 $1^{\text {CA hep }}$ mice compared to Cre-negative controls (TCA: $10.05 \%$ vs. $27.78 \%, p<0.001$; TDCA: $0.03 \%$ vs. $2.29 \%, p<0.05$; Figure $2 \mathrm{I}$ and $2 \mathrm{~J}$ ).

\section{Cholestasis causes up-regulation of compensatory bile acid transporters in livers, intestines and kidneys of Ctnnb1 ${ }^{\text {CA hep }}$ mice}

Due to high bile acid levels detected in serum and livers of Ctnnb1 $1^{\text {CA hep }}$ mice, we analyzed expression of various bile acid transporters, to test for putative changes in bile secretion, re-adsorption or excretion. Ctnnb1 ${ }^{\text {CA hep }}$ mice did not differ from controls with regards to expression of bile salt exporting pump (Bsep) also known as ATP-binding cassette transporter b11 (Abcb11) as evaluated by qPCR (Figure 3A). In contrast, mRNA levels of compensatory bile acid transporters including $A b c b 1$ (also known as multidrug resistance protein 1 (Mdr1)), Abcb4 (also known as $M d r 2$ ), and $A b c c 2$ (also known as multidrug resistance-associated protein 2 (Mrp2)) were significantly increased in $C t n n b 1^{C A \text { hep }}$ mice 
(Figure 3B-3D). Consistent with increased expression of compensatory bile acid transporters at the apical lumen, Ctnnb1 ${ }^{\text {CA hep }}$ mice displayed significantly reduced mRNA levels of the $\mathrm{Na}^{+}$-taurocholate co-transporting polypeptide (Ntcp, also known as Scl10a1) (Figure 3E). Furthermore, $C t n n b 1^{C A}$ hep mice expressed significantly increased
mRNA levels of Abcc4 (also known as Mrp4) favoring excretion of bile acids from hepatocytes into the systemic circulation (Figure 3F). Expression of organic aniontransporting polypeptide (Oatp) 1 and 2 as well as organic solute transporter $(O s t) \alpha$ and $\beta$ did not differ between Ctnnb1 ${ }^{\text {CA hep }}$ mice and controls (data not shown). Changes

A

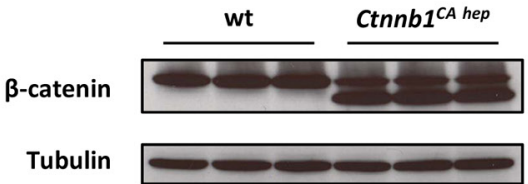

B

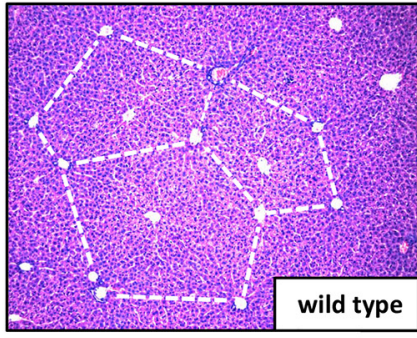

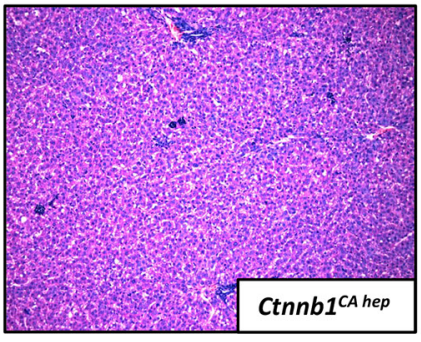

D

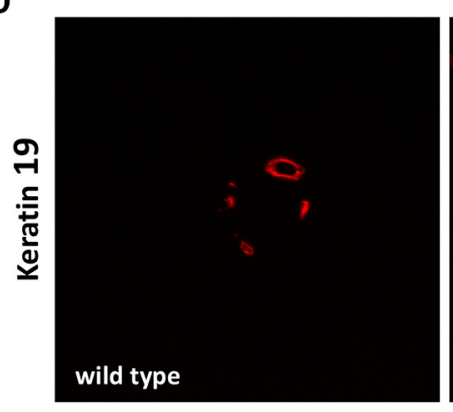

F
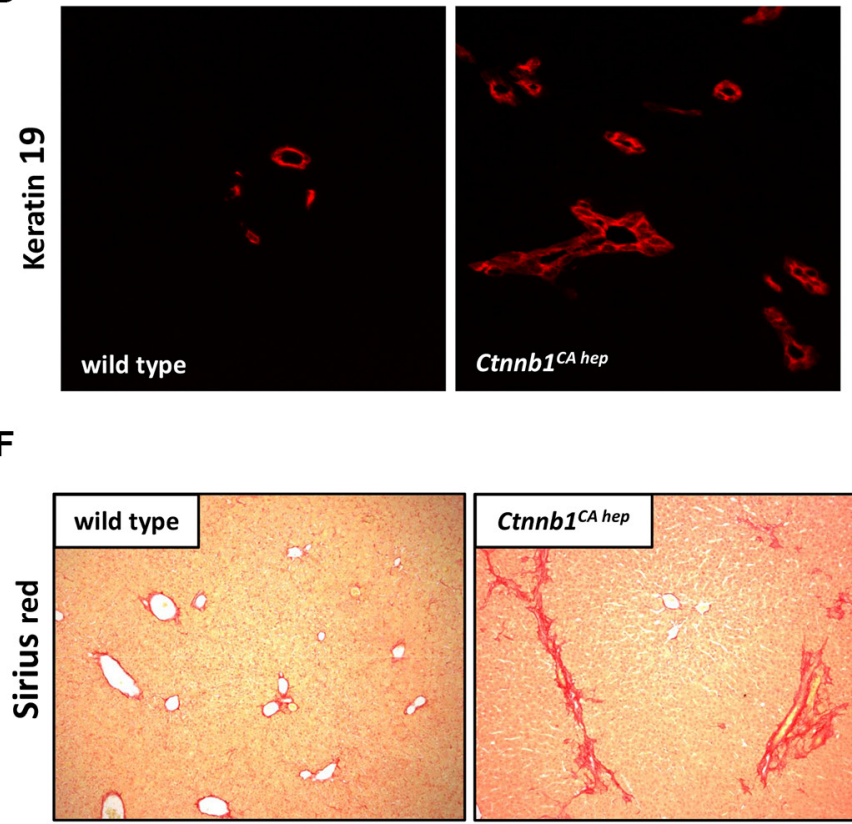
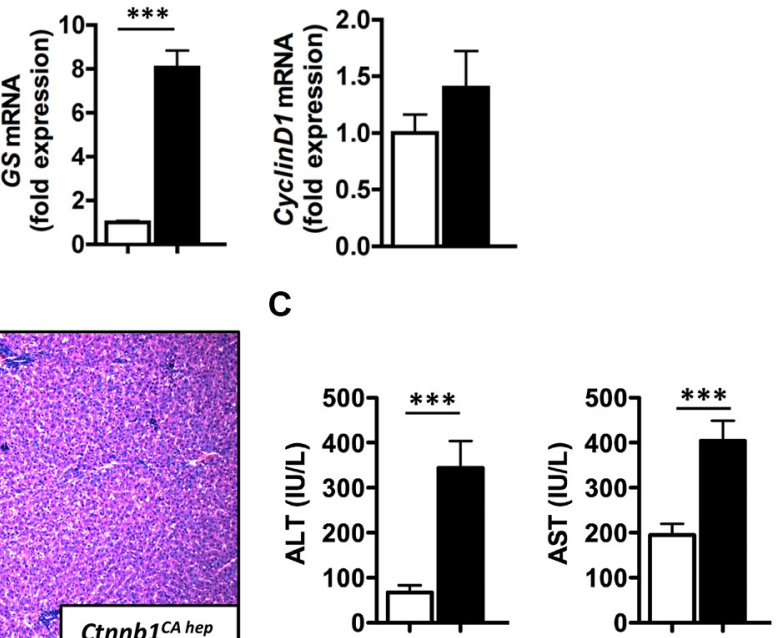

E

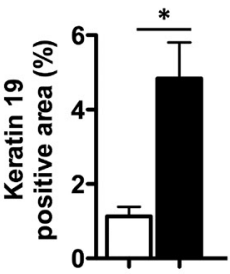

G
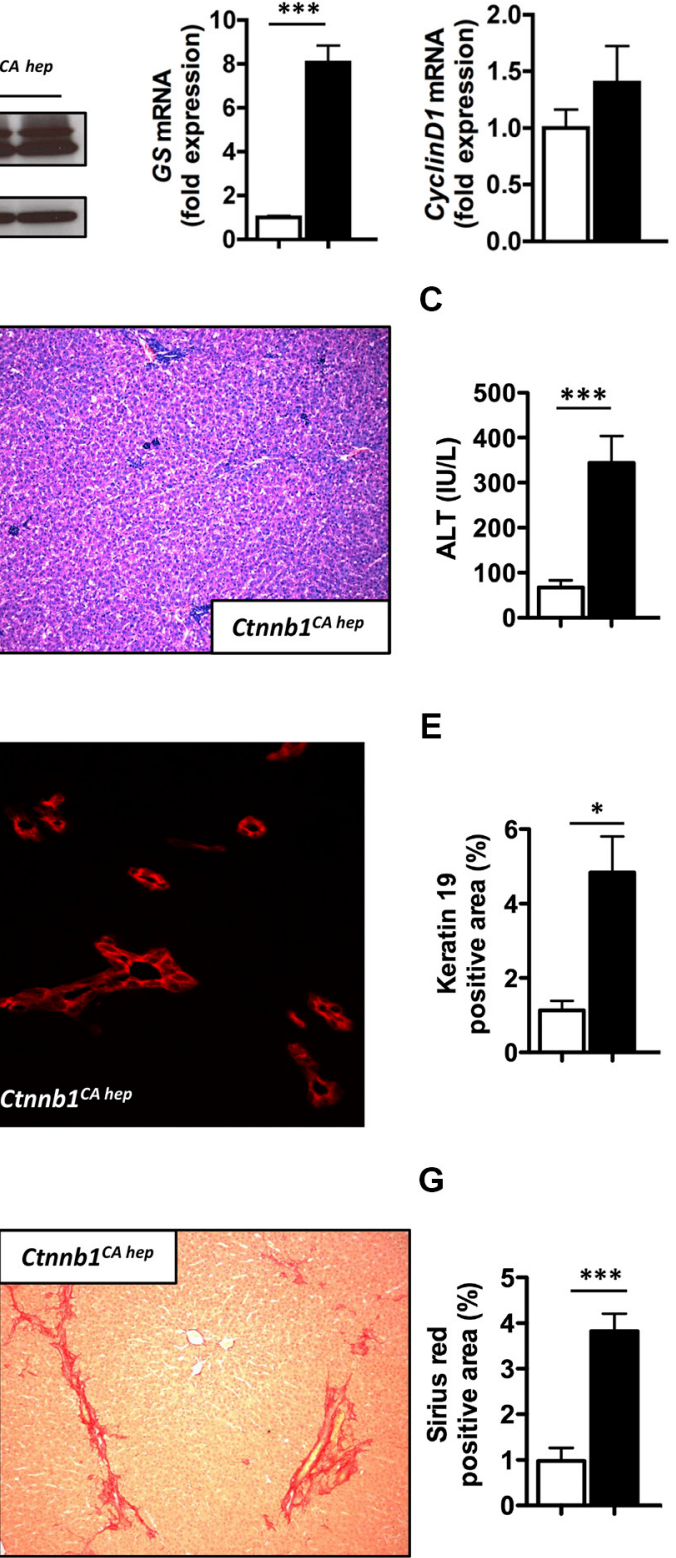

C

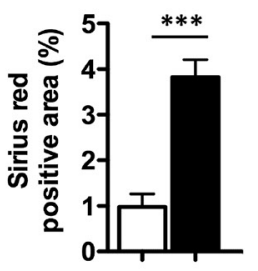

\section{wt controls}

Ctnnb1 ${ }^{\text {ca hep }}$

Figure 1: Continuous $\beta$-catenin signaling causes liver injury, bile duct proliferation and biliary type fibrosis. (A) Western blot of livers from $C t n n b 1^{C A \text { hep }}$ mice and wild type (wt) controls shows expression of a truncated version of $\beta$-catenin (faster migrating band) and a lower expressed full-length version as in wt controls (left panel). mRNA expression analysis using qPCR shows highly significant induction of the $\beta$-catenin target gene glutamine synthetase (GS) and slightly induced Cyclin D1 expression (right panel). Ctnnb1 ${ }^{\text {CA hep }}$ mice display disturbed liver architecture (B) and increased serum ALT and AST levels (C). Immunofluorescence staining for cholangiocyte marker Keratin 19 shows a significant increase of Keratin 19 positive cells in Ctnnb1 $^{\text {CA hep }}$ mice (D, E). Sirius red staining of wild type and Ctnnb1 ${ }^{\text {CA hep }}$ mice reveals biliary type fibrosis in $\beta$-catenin activated livers $(\mathbf{F}, \mathbf{G})$. Quantification of hepatic hydroxyproline levels confirmed increased collagen deposition in Ctnnb1 ${ }^{\text {CA hep }}$ livers $(\mathbf{H})$. Morphometric quantifications were done using Image J software. 
in expression of various transporters were confirmed at protein level (Figure 3G). In contrast to mRNA data, ABCB11 was reduced in $C$ tnnbl $1^{\text {CA hep }}$ mice compared to controls. These results suggest reactive up-regulation of compensatory bile acid transporters in response to increased intracellular bile acid levels in hepatocytes. In line with this hypothesis down-regulation of NTCP at basolateral membranes prevents bile acids derived from the enterohepatic circulation from entering hepatocytes of Ctnnb1 ${ }^{\text {CA hep }}$ mice preventing further accumulation of bile acids in hepatocytes (Figure $3 \mathrm{H}$ ).

Under physiological conditions, bile acids are extensively recycled in the intestine and the kidneys in order to maintain a functional bile acid pool. Enterocytes in the terminal ileum express the apical sodium-dependent bile acid co-transporter ( $A s b t$, also known as Slc10a2) at the luminal side for reabsorption of secreted bile acids and Ost $\alpha$ and Ost $\beta$ at the basolateral membrane for efflux of bile acids into the portal circulation [31-33]. Ctnnb1 ${ }^{\text {CA hep }}$ mice expressed significantly reduced mRNA levels of Asbt as well as Ost $\alpha$ and Ost $\beta$ compared to controls in enterocytes (Figure 4A and 4B). In line with reduced reabsorption of bile acids from the small intestine enterocytes of $C t n n b 1^{C A}$ hep mice expressed significantly lower mRNA levels of intestinal bile acid protein ( $B a b p)$, an intracellular transport system for bile acids from the apical to the basolateral membrane of enterocytes (Figure 4C) [33].

Bile acids are also filtrated in the glomerulus and reabsorbed by epithelial cells of proximal convoluted tubules in the kidney. In parallel to enterocytes in the terminal ileum, proximal convoluted tubule cells express Asbt at the luminal membrane for reabsorption of filtrated bile acids [34]. Asbt mRNA levels were significantly decreased in kidneys of Ctnnb1 ${ }^{\text {CA hep }}$ mice compared to Cre-negative littermate controls (Figure 4D). In contrast, mRNA levels of $A b c c 2$ and Abcc4 also located at the luminal membrane of proximal convoluted tubule cells but catalyzing transport of bile acids into the lumen were increased in Ctnnb1 ${ }^{\text {CA hep }}$ mice compared to Cre-negative littermate controls (Figure 4E). Proximal convoluted tubule cells also express $O s t \alpha$ and $\beta$ at the basolateral membrane for efflux of bile acids into the systemic circulation. Similar to enterocytes in the terminal ileum,
A

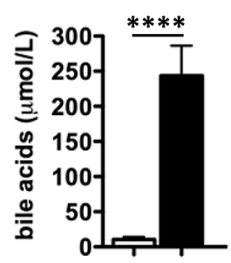

B

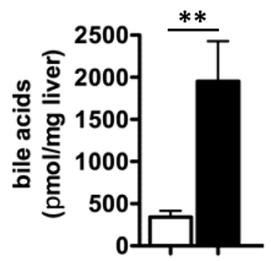

C

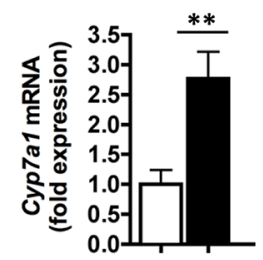

D
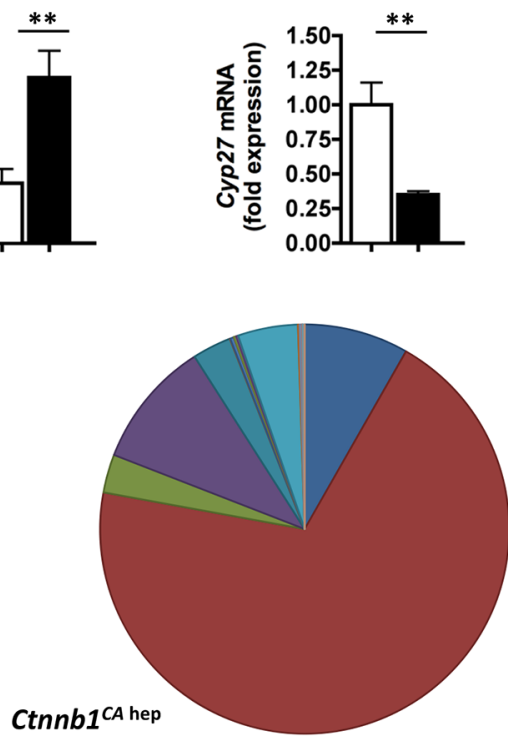

J

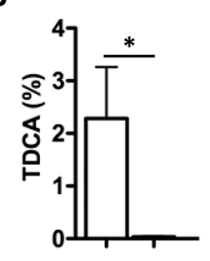

E

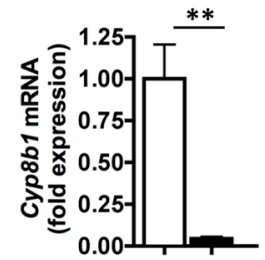

$\square \alpha-$ TMCA

$\square \beta$-TMCA

$\square \omega$-TMCA

$\square T C A$

$\square$ TCDCA

$\square$ TDCA

$\square$ TUDCA

$\square$ TLCA

$\square$ GCA

$\square \alpha-M C A$

$\square \beta-M C A$

$\square \omega$-MCA

$\square \mathrm{CA}$

$\square$ CDCA
G

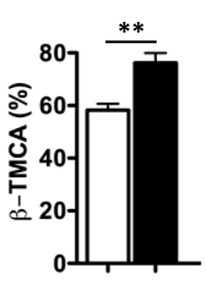

$\mathrm{H}$

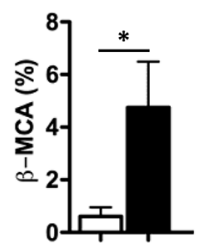

I

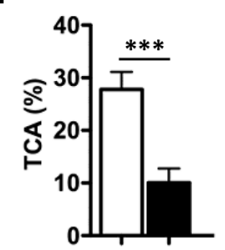

Figure 2: Ctnnb1 ${ }^{\text {CA hep }}$ mice are characterized by severe cholestasis and qualitative changes in bile acid composition. Ctnnb1 ${ }^{C A \text { hep }}$ mice displayed significantly increased serum (A) and hepatic (B) bile acid levels. Expression of Cyp $7 a 1$ (C) was significantly increased in $C t n n b 1^{C A}$ hep mice, whereas mRNA levels of Cyp27 (D) and Cyp8b1 (E) were decreased in livers with continuous $\beta$-catenin activation. The composition of the bile acid pool was altered in $C t n n b 1^{C A}{ }^{\text {hep }}$ mice $(\mathbf{F})$. The percentage of tauro- $\beta$-muricholic acid $(\beta-\mathrm{TMCA}$, $\mathbf{G})$ and $\beta$-muricholic acid $(\beta$-MCA, $\mathbf{H})$ of the total bile acid pool was significantly increased in $C t n n b 1^{C A}$ hep mice, whereas the percentage of taurine-conjugated cholic acid (TCA, I) and deoxycholic acid (TDCA, J) was decreased. 
mRNA levels of Ost $\alpha$ and $\beta$ were significantly reduced in kidneys of Ctnnb1 ${ }^{\text {CA hep }}$ mice compared to Cre-negative littermate controls (Figure 4F). In summary, these results suggest activation of compensatory transporter deregulation due to feedback mechanisms in the liver,

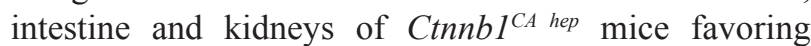
excretion of bile acids aiming to reduce the total bile acid pool. Expression levels of bile acid transporters also suggested that the high levels of bile acid were due to over-production rather than non-functional drainage.

To investigate the deregulation of bile acid homeostasis in more detail we examined the feedback mechanisms involved in the regulation of the bile acid pools including the enterokine fibroblast growth factor
15 (Fgf15), which is a critical regulator of bile acid homeostasis. Under physiological conditions, FGF15 is produced by enterocytes in response to FXR signaling due to increased intestinal bile acid levels and secreted into the portal blood stream. In the liver FGF15 binds to its receptor FGFR4 expressed by hepatocytes, which suppresses transcription of Cyp 7a1. Thus, high intraluminal levels of bile acids in the intestine suppress bile formation through a negative feed back mechanism executed by FGF15 and FGFR4 [35].

In line with increased bile formation and secretion into the small intestine, enterocytes of Ctnnb1 $1^{C A}$ hep mice expressed significantly increased Fgfl5 mRNA compared to Cre-negative littermate controls (Figure 5A).
A

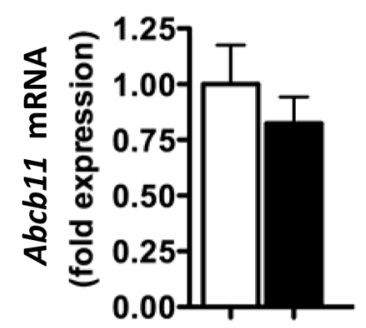

D

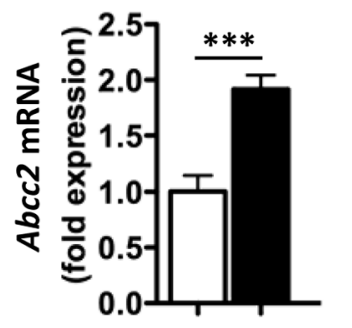

B

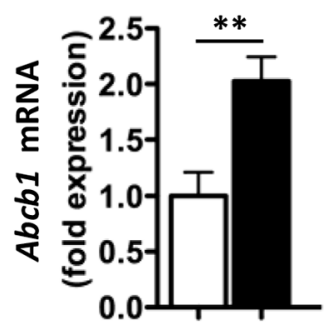

E

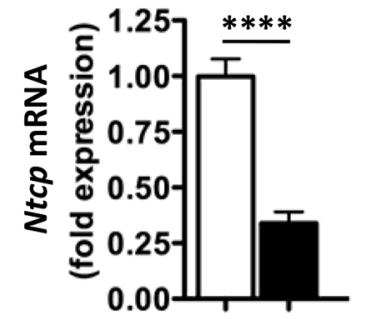

C

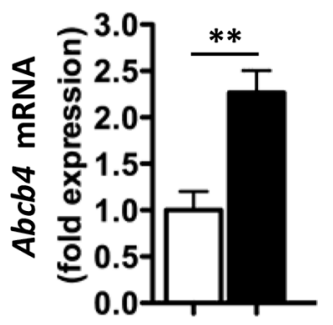

$\mathbf{F}$

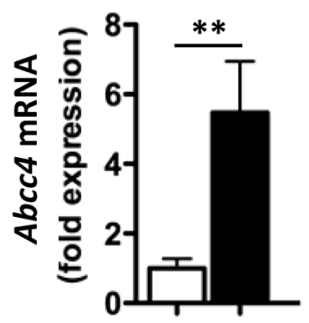

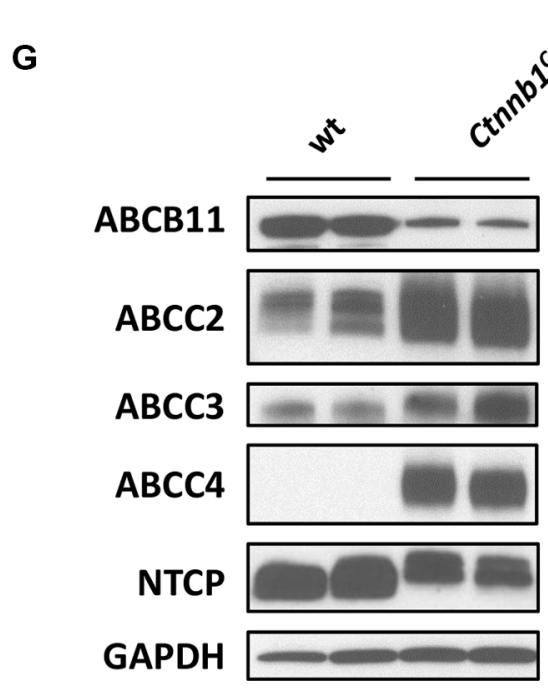

Figure 3: Ctnnb1 $^{\text {CA hep }}$ mice display adaptive changes in expression of compensatory bile acid transporters. The expression of $A b c b 11$ was not altered in $C t n n b 1^{C A}$ hep mice (A), whereas mRNA levels of compensatory bile acids transporters of $A b c b 1$ (B), $A b c b 4$ (C) and $A b c c 2$ (D) were significantly increased in $C t n n b 1^{C A}{ }^{h e p}$ mice. Expression of Ntcp was decreased (E) and Abcc4 increased in $C t n n b 1^{C A}$ hep mice $(\mathbf{F})$. Deregulation of bile acid handling transporters was confirmed on protein level by Western blot analysis with indicated antibodies (G). 
Intriguingly, levels of $\mathrm{Fxr}(\mathrm{Nr} / \mathrm{h} 4)$ were significantly decreased in the terminal ileum (Figure 5B). In the liver, Fgfr 4 mRNA levels were significantly reduced in Ctnnb1 $1^{\text {CA hep }}$ mice $(0.45$ vs. $1.00, p<0.01$; Figure 5C). Additionally, Fxr (Nr1h4) expression, which can be directly activated by increased intra-hepatocellular bile acid levels repressing Cyp7a1 expression, was significantly down-regulated in the livers of $C t n n b 1^{\text {CA hep }}$ mice (Figure 5D). In silico analyses of liver transporters and molecules involved in feedback control of bile synthesis revealed conserved TCF4 binding sites within the Fxr gene, suggesting a direct effect of $\beta$-catenin on Fxr expression (Figure 5E). Together, these data suggest that continuous $\beta$-catenin activation results in disruption of the FXR-FGF15-FGFR4-CYP7A1 axis in Ctnnb1 $1^{\text {CA hep }}$ mice and loss of feedback control of bile acid production in the liver.

\section{Cholestasis in $C_{t n n b 1}{ }^{\text {CA hep }}$ mice is not a consequence of developmental abnormalities}

$\beta$-catenin plays a crucial role during embryogenesis. Albumin-Cre mice express Cre recombinase as early as day 15.5 of embryonic development [36]. Accordingly, the phenotype of Ctnnb1 $1^{C A}$ hep mice might result from developmental abnormalities. To address this caveat we generated mice in which hepatocyte-specific expression of the Cre recombinase can be temporally controlled. To test the validity of the system we crossed Serum albumin $\mathrm{CreER}^{T 2}\left(\mathrm{SA}-\mathrm{CreEr}^{T 2}\right)$ mice, in which the expression of the Cre recombinase is inducible by tamoxifen, to a reporter mouse line in which the red fluorescent protein tdTomato is located after a loxP-flanked STOP cassette. Hence the offspring of this breeding ( $\mathrm{SA}-\mathrm{CreEr}^{\text {TTom }}$ ) express tdTomato only in recombinated cells after removal of the STOP cassette induced by tamoxifen injection. SA-CreEr ${ }^{\text {TTom }}$ mice were treated with intraperitoneal injections of tamoxifen at the age of 10 weeks for five consecutive days and sacrificed 7 days after the last injection (Figure 6A). Fluorescence microscopy revealed that tdTomato is only expressed in hepatocytes (counterstaining with DAPI) while cholangiocytes of bile ducts display no red fluorescence confirming that the SA-Cre recombinase is specifically active in hepatocytes (Figure 6B). Subsequently, we generated tamoxifen inducible $C t n n b 1^{T C C A}$ hep mice, by crossing Ctnnb1 exon 3 floxed mice to Serum albumin CreER ${ }^{T 2}$ mice. Activity of Cre recombinase and thus recombination was controlled by intraperitoneal injection of tamoxifen according to the same injection schedule as for SA-CreEr ${ }^{\text {TTom }}$ mice. Intriguingly, Ctnnbl ${ }^{T C C A}$ hep mice displayed elevated serum ALT and AST levels (ALT: 63.5 vs. $5.5 \mathrm{IU} / \mathrm{L}$, $p<0.01$; AST: 200.5 vs. 63 IU/L, $p<0.01$; Figure $6 \mathrm{C}$ ), as well as elevated bile acid (BA) levels (AP: 65 vs. $40 \mathrm{IU} / \mathrm{L}, p<0.01$; BA: 131.1 vs. $28.2 \mu \mathrm{mol} / \mathrm{L}, p<0.01$; Figure 6D). Only minor signs of fibrosis, as evaluated by Sirius red staining and hepatic hydroxyproline levels, could be detected, which might be due to the short period of $\beta$-catenin induction in this system (Figure 6E and $6 \mathrm{~F}$ ). Analogous to $C$ tnnb1 $1^{\text {CA hep }}$ mice, Ctnnb $1^{\text {TCCA hep }}$ mice displayed a reactive bile duct phenotype indicating cholestasis (Supplementary Figure S3A), with no signs

$\underline{\text { Terminal lleum }}$

A

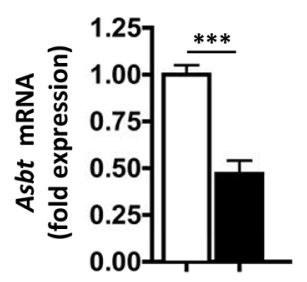

D

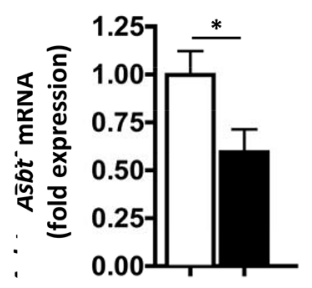

B

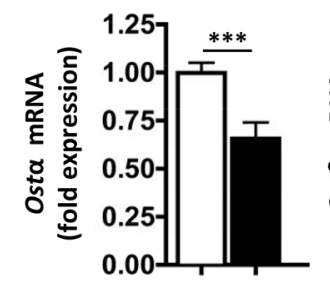

E

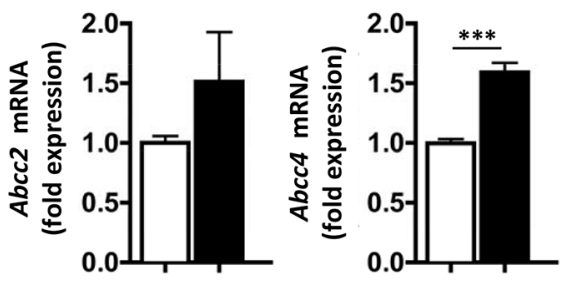

C
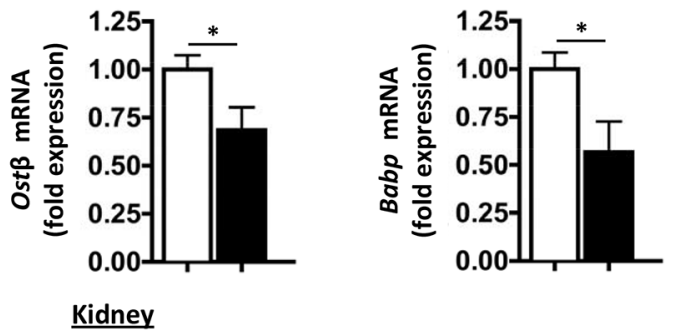

$\mathbf{F}$

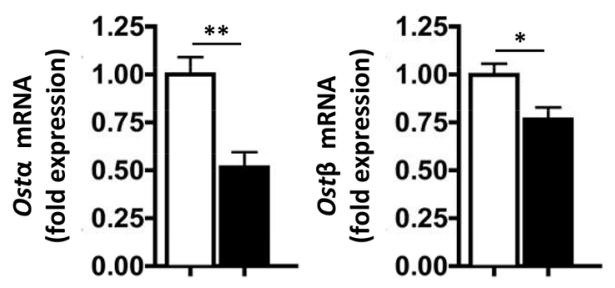

Figure 4: Cholestasis causes deregulation of compensatory bile acid transporters in intestines and kidneys of Ctnnb1 ${ }^{\text {CA hep }}$ mice. Enterocytes in the terminal ileum of $C t n n b 1^{C A}$ hep mice displayed significantly reduced mRNA levels of the bile acid handling transporters $A s b t(\mathbf{A})$, Ost $\alpha$ and $\beta(\mathbf{B})$ and $B a b p(\mathbf{C})$. Proximal convoluted tubule cells in kidneys of $C t n n b 1^{C A}$ hep mice displayed significantly reduced mRNA levels of $A s b t(\mathbf{D})$. In contrast, mRNA levels of $A b c c 2$ and $A b c c 4$ were increased in $C t n n b 1^{C A}$ hep mice (E). Expression of Ost $\alpha$ and $\beta$ were significantly reduced in kidneys of $C t n n b 1^{C A}$ hep mice $(\mathbf{F})$. 
of hyperproliferation (Supplementary Figure S3B) or apoptosis (Supplementary Figure S3C) as compared to control mice.

Furthermore, Ctnnb1 TCCA hep mice displayed the same expression pattern of enzymes involved in bile acid synthesis as Ctnnb1 $1^{\text {CA hep }}$ mice, including up-regulation of Cyp7a1 and down-regulation of Cyp27 and Cyp8b1 (Figure 7A-7C) as well as downregulation of Cyp2b10 (Supplementary Figure S3D). Additionally, Fgfr4 was also significantly down-regulated in Ctnnb1TC ${ }^{C A}$ hep mice (Figure 7D). Moreover, Fxr expression was significantly reduced in livers as well as in the terminal ileum of Ctnnb1 ${ }^{T C C A}$ hep mice (Figure 7E and Supplementary Figure S3E), providing further evidence for decoupling of the FXR-FGF15-FGFR4-CYP7A1 axis in response to continuous $\beta$-catenin signaling. Ctnnb1 TC ${ }^{C A}$ hep mice were also characterized by deregulation of hepatic bile acid transporters similar to $C$ tnn $b 1^{C A}$ hep mice. $A b c b 11$ mRNA levels were significantly reduced in livers of $C t n n b 1^{\text {TCCA hep }}$ mice, whereas expression of $A b c c 2$ was increased (Figure $7 \mathrm{~F}$ and $7 \mathrm{G}$ ). Consistent with results observed in $\mathrm{Ctnnb1}^{\mathrm{CA}}$ hep mice, Ctnnb1TC ${ }^{C A}$ hep mice displayed significantly reduced mRNA levels of Ntcp (Figure 7H) and increased mRNA levels of Abcc4 (Figure 7I). The expression of hepatic transporters was also quantified on protein level, where the same trend as in the qPCR analyses was observed (Figure 7J).

In summary, these results suggest that severe cholestasis in $C$ tnnb1 ${ }^{\text {CA hep }}$ mice is a direct consequence of continuous $\beta$-catenin signaling and not related to potential disturbances of liver architecture as a consequence of genetic recombination during embryonic development.

\section{DISCUSSION}

$\beta$-Catenin signaling has been associated both with liver development, homeostasis and disease. Activation of the Wnt/ $\beta$-catenin pathway is frequently observed

\section{$\underline{\text { Terminal lleum }}$}

A

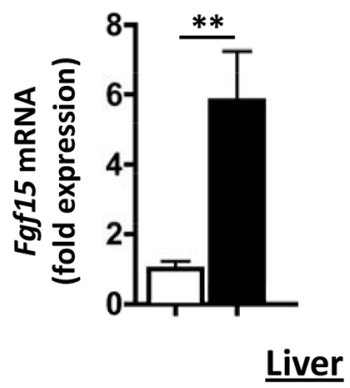

B

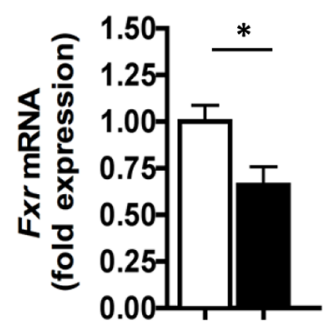

C

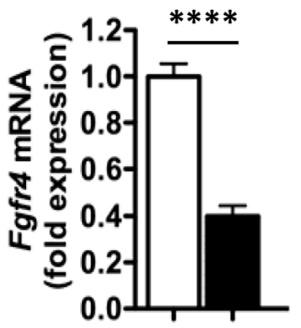

D

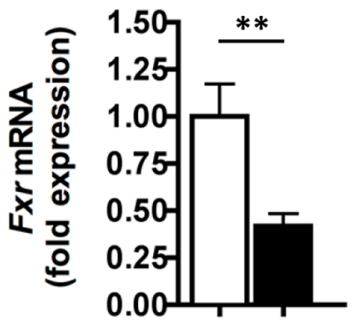

wt controls

Ctnnb1 1 CA hep

E

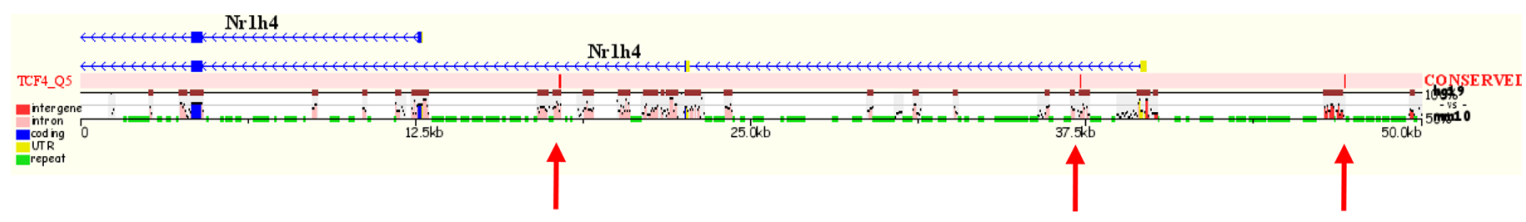

Figure 5: Deregulation of molecules involved in bile acid homeostasis in Ctnnb1 $^{\text {CA hep }}$ mice. Expression of the enterokine Fgf15 was significantly increased in enterocytes of Ctnnb1 ${ }^{C A}$ hep mice (A), while Fxr was significantly down-regulated (B). The FGF15 responsive receptor Fgfr 4 was significantly decreased in the livers of $C t n n b 1^{C A}$ hep mice (C). mRNA levels of Fxr were also decreased in livers of Ctnnb1 ${ }^{\text {CA hep }}$ mice compared to controls (D). In silico screening for human/mouse conserved $\beta$-catenin binding sites using the ECR browser (http://ecrbrowser.dcode.org) identifies conserved binding sites in the promoter region of the FXR encoding gene $\mathrm{Nr} / \mathrm{h} 4$ (E). Arrows indicate the locations of the conserved TCF4 binding sites. 
in HCC, and missense mutations in exon 3 of Ctnnb1 exhibit a histologically more aggressive phenotype and are associated with severe cholestasis, vascular invasion and recurrence of disease after orthotopic liver transplantation [24, 37]. In line with data obtained from mice it was suggested that cholestasis is a marker of HCCs with activating $\beta$-catenin mutations [38]. Aside from its well-established role in diverse neoplastic diseases of the liver, active $\beta$-catenin signaling has been implicated in hepatic fibrosis important for stellate cell activation, and $\mathrm{NASH}$, highlighting its role for the regulation of metabolic processes in the liver [27].

In the present study we generated a mouse model to investigate the consequences of continuous $\beta$-catenin signaling in hepatocytes on liver biology. Using two mouse models of fetal and post-natal $\beta$-catenin activation we observed a cholestatic phenotype within days of $\beta$-catenin activation. A hallmark of both mouse models were the enormously increased bile acid levels in serum and livers compared to Cre-negative controls. Although $C$ tnnb1 ${ }^{C A}$ hep mice display severely disturbed liver architecture and biliary type of fibrosis our data suggest no defects in bile drainage due to obstipation, because $C t n n b 1 \mathrm{TC}^{C A}$ hep mice also suffer from cholestasis and highly elevated bile acid levels without prominent liver pathology and fibrosis. Additionally, the striking deregulation of molecules involved in bile acid synthesis pathways provides evidence for accelerated de novo synthesis of bile acids rather than an anamical cause of cholestasis. Our data are in line with studies using conditional Apc knockouts to induce stable $\beta$-catenin expression in hepatocytes that demonstrate defects in liver zonation and a positive effect of activated $\mathrm{Wnt} / \beta$-catenin signaling on bile acid metabolism and transport as well as cholesterol and drug metabolism [10, 39]. In one of these studies, upregulation of Cyp7a1, Cyp27a1 and CAR in liver from $A p c$ knockout mice with constitutively activated $\beta$-catenin was reported and suggested that Cyp27al but not Cyp $7 a 1$ is a direct target of $\beta$-catenin [10]. In contrast, we report significant downregulation of Cyp27al in Ctnnb1 ${ }^{\text {CA hep }}$ and $C t n n b 1^{\text {TCCA hep }}$ mice. Furthermore, the expression pattern of enzymes and transporters involved in bile acid formation and secretion argues against a strictly CAR-mediated adaptive response in $C t n n b 1^{C A}$ hep and Ctnnb1TC ${ }^{C A}$ hep mice.

Additionally, it was previously shown that Ctnnb1 $1^{\text {shep }}$ mice are protected from acetaminophen induced hepatotoxicity due to lack of CYP2E1 expression [19]. The authors also reported reduced expression of Cyp 1 a2
A

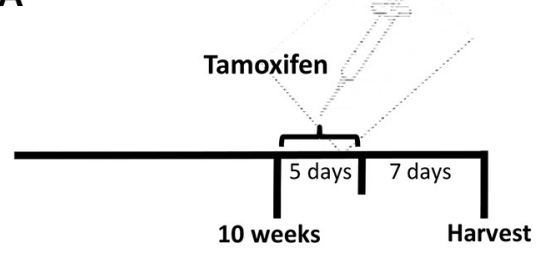

C
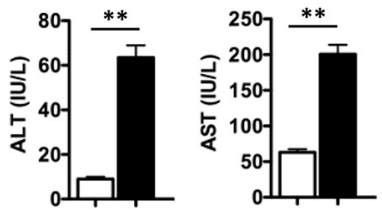

B
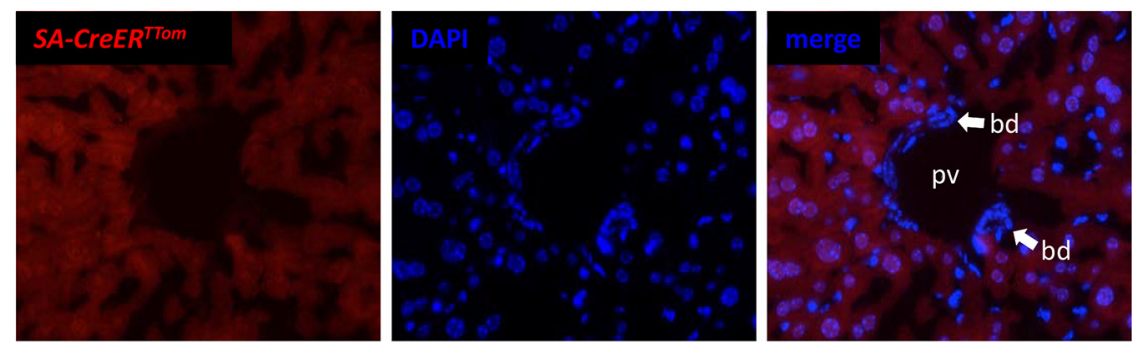

D

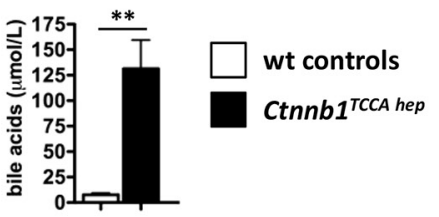

$\mathbf{F}$

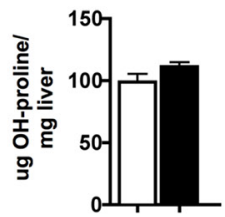

Figure 6: Cholestasis in Ctnnb1TC ${ }^{\text {CA hep }}$ mice is not a consequence of developmental abnormalities. Tamoxifen injection scheme for $S A$-CreER ${ }^{T T o m}$ and Ctnnb1 ${ }^{T C C A}$ hep mice (A). Tamoxifen administration leads to the activation of the Cre recombinase and consequently to expression of tdTomato (red fluorescence) in hepatocytes but not in cholangiocytes (counterstaining with DAPI, bd = bile duct, pv = portal vein) $(\mathbf{B})$. Serum ALT, AST and bile acid levels were significantly increased in Ctnnb1 $1^{T C C A h e p}$ mice (C and D). Ctnnb1 $1^{T C C A}$ hep mice display only minor signs of fibrosis $(\mathbf{E}$ and $\mathbf{F})$. 
and Cyp2c29 but unchanged expression of Cyp1a1 and Cyp3al1 in livers of Ctnnb1 $1^{\text {thep }}$ mice suggesting differential rather than global regulation of CYP450 isoforms by $\beta$-catenin. Direct transcriptional regulation of particular CYP450 isoforms by $\beta$-catenin is further supported by data obtained in mice with liver tumors with activating $\beta$-catenin mutations [40]. In this respect, it was demonstrated that glutamine synthetase positive tumors express increased levels of CYP1A, CYP2B, CYP2C and CYP2E1. Furthermore, the authors provided evidence for direct activation of CYP2B1 by $\beta$-catenin using luciferase assays and amplification of 2,3,7,8-tetrachlordibenzopdioxin mediated activation of a dioxin-responsive reporter gene assay by $\beta$-catenin [40].
Bile acid synthesis is subject to a tightly controlled feedback mechanism under physiological conditions, depending on bile acid levels in the liver and in the ileum. We observed significantly increased mRNA levels of the FXRdependent enterokine FGF15 in enterocytes of $C t n n b 1^{\text {CA hep }}$ mice. However, FXR levels were significantly decreased in the terminal ileum and in livers of $C$ tnnb $1^{\text {CA hep }}$ mice. Despite high FGF15 levels in enterocytes, Fgfr4 expression was reduced in hepatocytes of $C t n n b 1^{C A}{ }^{\text {hep }}$ mice. We speculate that $\beta$-catenin might directly interfere with the bile acid feedback loop by downregulation of Fxr expression. An inverse correlation of FXR and $\beta$-catenin expression was previously observed in HCC and Fxr knockout mice develop $\mathrm{HCC}$ through activation of Wnt/ $\beta$-catenin signaling [41].
A

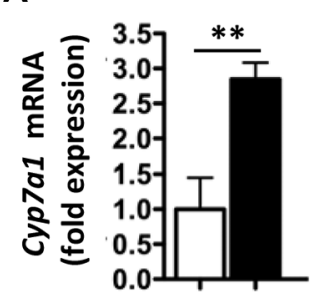

D

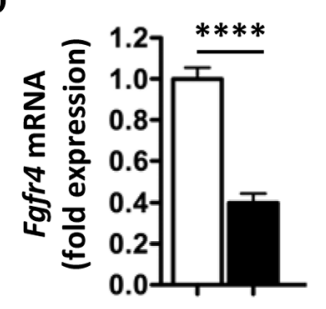

G

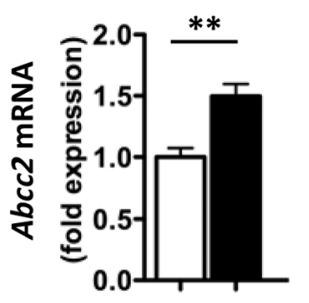

I

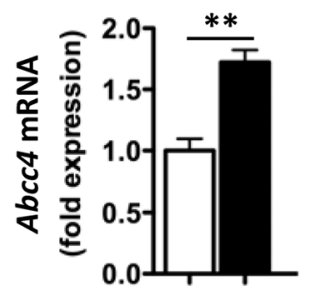

B

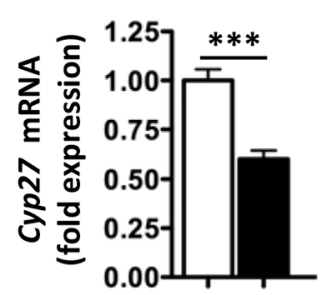

E

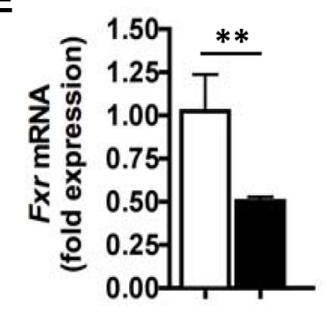

H

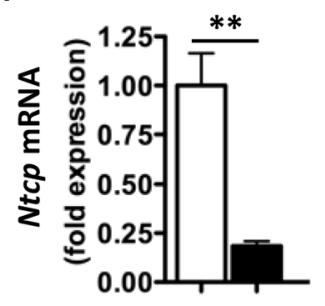

$\square$ wt controls
Ctnnb1 $^{\text {TCCA hep }}$
C

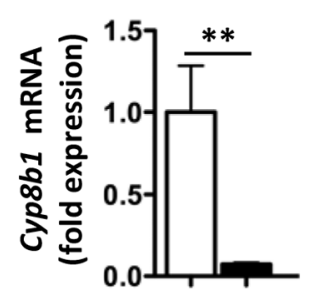

$\mathbf{F}$

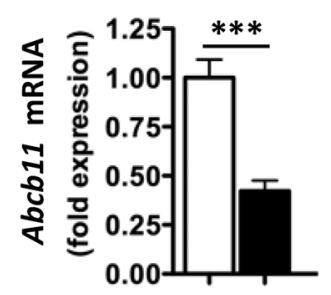

J

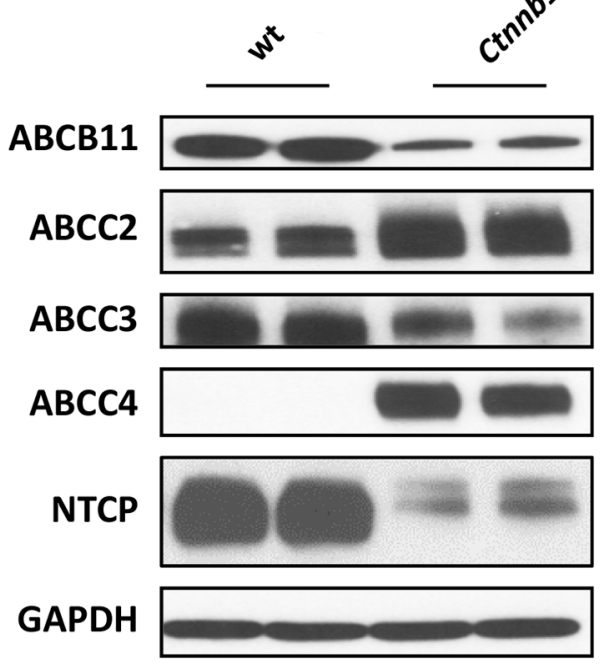

Figure 7: Ctnnb1TC ${ }^{\text {A hep }}$ mice display deregulation of key enzymes for bile acid synthesis and hepatic transport. Expression of Cyp7a1 (A) was increased in Ctnnb1 $1^{T C C A}$ hep mice, whereas mRNA levels of Cyp27 (B), Cyp8b1 (C), Fgfr4 (D) and Fxr (E) were significantly reduced. mRNA levels of $A b c b 11$ were reduced (F) and of $A b c c 2$ increased in $C t n n b 1^{T C C A h e p}$ mice (G). Downregulation of $N t c p(\mathbf{H})$ and upregulation of $A b c c 4(\mathbf{I})$ in livers with continuous $\beta$-catenin activation. Deregulation of bile acid transporters was confirmed at protein level by Western blot analysis with indicated antibodies $(\mathbf{J})$. 
In our model, cholestasis in Ctnnb1 ${ }^{C A}$ hep mice was associated with compensatory up- and down-regulation of accessory bile acid transporters in hepatocytes as well as in enterocytes in the terminal ileum and in epithelial cells of proximal convoluted tubules in the kidney. We observed increased expression of Abcc4 in livers of Ctnnb1 ${ }^{\text {CA hep }}$ mice suggesting activation of a Constitutive Androstane Receptor (CAR)-mediated protection pathway leading to secondary detoxification of bile acids. However, expression of Cyp2b10, another classical CAR target gene, was completely abolished in Ctnnb1 ${ }^{C A}$ hep and Ctnnb1TC ${ }^{C A}$ hep mice. These results indicate that upregulation of enzymes and transporters involved in bile acid detoxification is not strictly CAR mediated and suggest a more complex mechanism in the induction of phase I, II and III detoxification systems in hepatocytes with continuous $\beta$-catenin signaling.

In contrast to our results, it was previously demonstrated that $C$ tnnbl $1^{\text {thep }}$ mice display bile canalicular abnormalities, bile secretory defects and intrahepatic cholestasis [11]. However, bile acid levels in livers and serum were only modestly increased ( 2-3-fold) suggesting that observed cholestasis is the consequence of anatomical and structural abnormalities in Ctnnb1 $1^{\text {shep }}$ mice.

In summary, our study provides further evidence linking $\beta$-catenin signaling to deregulations of individual CYP450 isoforms, bile acid formation and therefore cholestatic liver disease. Our data further suggest that hepatocytes with continuous $\beta$-catenin signaling as observed in a significant subgroup of patients with $\mathrm{HCC}$ is associated with fibrosis due to cholestasis and accompanying changes in expression of various complementary bile acid transporters. Given the importance of different CYP450 isoforms and transporters for inactivation and export of various widely clinically used anticancer drugs our study improves our understanding regarding resistance of $\mathrm{HCC}$ with activating $\beta$-catenin mutations against cytotoxic therapy. Further studies are necessary, to understand whether the observed hepatic injury is a result of bile acid accumulation or a direct consequence of $\beta$-catenin activation. Additionally, it will be important to study the functionality of the bile secretory system in more detail in affected mice and to investigate whether bile duct proliferation is a primary phenotype or rather a regenerative response to chronic hepatocellular damage.

\section{MATERIALS AND METHODS}

\section{Mice}

Albumin-Cre mice (C57BL/6-Tg(Alb-cre)21Mgn/J) were obtained from the Jackson laboratories [42]. Mice in which exon 3 of the $\beta$-catenin gene is flanked by loxP sites were described previously [43]. Mice with a loxP flanked exon 3 of the Ctnnb1 gene were crossed to Albumin-Cre mice to obtain mice with hepatocyte specific expression of a dominant stable form of $\beta$-catenin (Ctnnb1 ${ }^{\text {CA hep }}$ mice). Ctnnb1 ${ }^{\text {CA hep }}$ mice as well as their wild type littermates, which served as controls were sacrificed and analyzed at the age of 21 days.

Serum albumin CreER $R^{T 2}\left(S A-C r e E R^{T 2}\right)$ mice were described previously [44]. The expression of Cre recombinase in these mice is also under control of an Albumin promoter. In contrast to Albumin-Cre mice, the Cre recombinase protein is fused to the ligand-binding domain of a mutated estrogen receptor $\left(\mathrm{Cre}-\mathrm{ERT}^{2}\right)$. The Cre-ERT ${ }^{2}$ fusion protein is sequestered in the cytoplasm but undergoes a conformation change in the presence of 4-hydroxy-tamoxifen and is then able to migrate to the nucleus removing loxP flanked DNA sequences. The resulting offspring are termed Ctnnbl temporally controlled constitutive active (TCCA) in hepatocytes $\left(C t n n b 1^{\text {TCCA hep }}\right)$ mice. Adult mice at the age of 10 weeks received intra-peritoneal injections of tamoxifen $(10 \mu \mathrm{g} / \mathrm{g}$ body weight, Sigma Aldrich) for five consecutive days and were sacrificed and analyzed 7 days after the last injection. Cre-negative littermates receiving identical treatment as Cre-positive animals were exclusively used as controls throughout the entire study. All experiments performed in this study were approved by the local ethical committee (BMWFW-66.009/0134-WF/V/3b/2015).

\section{Serum parameters}

Serum parameters were quantified using standard methods or as described previously $[45,46]$.

\section{Histology}

The left liver lobe was cut in the middle and used for histology. Tissue was fixed in $10 \%$ formalin over night at room temperature and subsequently embedded in paraffin. Five $\mu \mathrm{m}$ thick sections were cut and used for staining. Sirius red staining was performed as described previously [47]. Immunofluorescence staining for desmin was performed as described previously [48]. Immunofluorescence staining for Keratin 19 was performed using TROMA-III antibody (1:500, Developmental Studies Hybridoma Bank) using snap frozen liver tissue following fixation in 100\% acetone for 10 minutes at -20 degree. Detailed protocols for each staining will be provided upon request.

\section{Quantitative real-time PCR}

mRNA was isolated using $\mathrm{TRI}^{\circledR}$ Reagent RNA Isolation Reagent (Sigma Aldrich) following the instructions of the manufacturer. Complementary DNA (cDNA) was generated using the High Capacity cDNA Reverse Transcription Kit (Applied Biosystems) following 
the instructions of the manufacturer. $\mathrm{iQ}^{\mathrm{TM}} \mathrm{SYBR}^{\circledR}$ Green Supermix (BioRad) was used for quantitative PCR (qPCR). Primer sequences were obtained from the qPrimerDepot (http://mouseprimerdepot.nci.nih.gov) and will be provided upon request. Melting curve analysis and agarose gel electrophoresis was performed to assess the quality of primers and the qPCR.

\section{Immunoblotting}

Protein extracts of liver samples were prepared using RIPA buffer and protein concentration was determined using a BCA assay (Pierce). Western blotting was performed using standard methods as described previously $[47,49,50]$.

\section{Bile acid quantification}

Bile acids were quantified as described previously

\section{Image J}

Morphometric quantification of images was performed using Image J software (Image J 1.48f, National Institutes of Health).

\section{In silico screening}

In silico screening was performed in https:// ecrbrowser.dcode.org/.

\section{ACKNOWLEDGMENTS}

We are thankful to Martha Seif (Division of Gastroenterology and Hepatology) as well as Helga Schachner and Michaela Schlederer (both Clinical Institute of Pathology) for their technical assistance.

\section{CONFLICTS OF INTEREST}

The authors declare that there is no conflicts of interest regarding this manuscript.

\section{GRANT SUPPORT}

This work was supported by funds from the Herzfelder'sche Familienstiftung and from the Oesterreicheische Nationalbank (Oesterreichische Nationalbank, Anniversary Fund, project number: 15608) and grant F3517 from the Austrian Science Foundation (to MT). CHÖ was funded by an APART-fellowship of the Austrian Academy of Sciences. GE receives funding from the Austrian Science Foundation (FWF) (project numer: P 27616).

\section{REFERENCES}

1. Clevers H, Nusse R. Wnt/ $/$-catenin signaling and disease. Cell. 2012; 149:1192-1205.

2. Gonzalez FJ. Role of $\beta$-catenin in the adult liver. Hepatology (Baltimore, Md). 2006; 43:650-653.

3. Klaus A, Birchmeier W. Wnt signalling and its impact on development and cancer. Nature reviews Cancer. 2008; 8:387-398.

4. Huelsken J, Vogel R, Brinkmann V, Erdmann B, Birchmeier C, Birchmeier W. Requirement for beta-catenin in anterior-posterior axis formation in mice. The Journal of cell biology. 2000; 148:567-578.

5. Grigoryan T, Wend P, Klaus A, Birchmeier W. Deciphering the function of canonical Wnt signals in development and disease: conditional loss- and gain-offunction mutations of -catenin in mice. Genes Dev. 2008; 22:2308-2341.

6. Micsenyi A, Tan X, Sneddon T, Luo JH, Michalopoulos GK, Monga SPS. $\beta$-Catenin is temporally regulated during normal liver development ${ }^{3}$. Gastroenterology. 2004; 126:1134-1146.

7. Burke ZD, Reed KR, Phesse TJ, Sansom OJ, Clarke AR, Tosh D. Liver Zonation Occurs Through a $\beta$-CateninDependent, c-Myc-Independent Mechanism. YGAST. 2009; 136:2316-2324.e2313.

8. Colletti M, Cicchini C, Conigliaro A, Santangelo L, Alonzi T, Pasquini E, Tripodi M, Amicone L. Convergence of Wnt Signaling on the HNF4 $\alpha$-Driven Transcription in Controlling Liver Zonation. YGAST. 2009; 137:660-672.

9. Tan X, Behari J, Cieply B, Michalopoulos GK, Monga SPS. Conditional Deletion of $\beta$-Catenin Reveals Its Role in Liver Growth and Regeneration. Gastroenterology. 2006; 131:1561-1572.

10. Gougelet A, Torre C, Veber P, Sartor C, Bachelot L, Denechaud PD, Godard C, Moldes M, Burnol AF, Dubuquoy C, Terris B, Guillonneau F, Ye T, et al. T-cell factor 4 and beta-catenin chromatin occupancies pattern zonal liver metabolism in mice. Hepatology. 2014; 59:2344-2357.

11. Yeh TH, Krauland L, Singh V, Zou B, Devaraj P, Stolz DB, Franks J, Monga SPS, Sasatomi E, Behari J. Liverspecific $\beta$-catenin knockout mice have bile canalicular abnormalities, bile secretory defect, and intrahepatic cholestasis. Hepatology. 2010; 52:1410-1419.

12. Claudel T, Zollner G, Wagner M, Trauner M. Role of nuclear receptors for bile acid metabolism, bile secretion, cholestasis, and gallstone disease. Biochimica et biophysica acta. 2011; 1812:867-878.

13. Cuperus FJ, Claudel T, Gautherot J, Halilbasic E, Trauner M. The role of canalicular ABC transporters in cholestasis. Drug metabolism and disposition. 2014; 42:546-560. 
14. Sekine S, Gutiérrez PJA, Yu-Ang Lan B, Feng S, Hebrok M. Liver-specific loss of $\beta$-catenin results in delayed hepatocyte proliferation after partial hepatectomy. Hepatology. 2007; 45:361-368.

15. Nejak-Bowen KN, Thompson MD, Singh S, Bowen WC, Dar MJ, Khillan J, Dai C, Monga SP. Accelerated liver regeneration and hepatocarcinogenesis in mice overexpressing serine-45 mutant $\beta$-catenin. Hepatology. 2010; 51:1603-1613.

16. Behari J, Yeh TH, Krauland L, Otruba W, Cieply B, Hauth B, Apte U, Wu T, Evans R, Monga SPS. LiverSpecific $\hat{I}^{2}$-Catenin Knockout Mice Exhibit Defective Bile Acid and Cholesterol Homeostasis and Increased Susceptibility to Diet-Induced Steatohepatitis. AJPA. 2010; 176:744-753.

17. Lehwald N, Tao GZ, Jang KY, Papandreou I, Liu B, Liu B, Pysz MA, Willmann JK, Knoefel WT, Denko NC, Sylvester KG. $\beta$-Catenin Regulates Hepatic Mitochondrial Function and Energy Balance in Mice. YGAST. 2012; 143:754-764.

18. Liu S, Yeh TH, Singh VP, Shiva S, Krauland L, Li H, Zhang P, Kharbanda K, Ritov V, Monga SPS, Scott DK, Eagon PK, Behari J. $\beta$-Catenin is essential for ethanol metabolism and protection against alcohol-mediated liver steatosis in mice. Hepatology. 2012; 55:931-940.

19. Sekine S, Lan BY-A, Bedolli M, Feng S, Hebrok M. Liver-specific loss of $\beta$-catenin blocks glutamine synthesis pathway activity and cytochrome $\mathrm{p} 450$ expression in mice. Hepatology (Baltimore, Md). 2006; 43:817-825.

20. de La Coste A, Romagnolo B, Billuart P, Renard CA, Buendia MA, Soubrane O, Fabre M, Chelly J, Beldjord C, Kahn A, Perret C. Somatic mutations of the beta-catenin gene are frequent in mouse and human hepatocellular carcinomas. Proceedings of the National Academy of Sciences of the United States of America. 1998; 95:8847-8851.

21. Devereux TR, Anna CH, Foley JF, White CM, Sills RC, Barrett JC. Mutation of beta-catenin is an early event in chemically induced mouse hepatocellular carcinogenesis. Oncogene. 1999; 18:4726-4733.

22. Calvisi DF, Factor VM, Ladu S, Conner EA, Thorgeirsson SS. Disruption of $\beta$-catenin pathway or genomic instability define two distinct categories of liver cancer in transgenic mice. Gastroenterology. 2004; 126:1374-1386.

23. Calvisi DF, Conner EA, Ladu S, Lemmer ER, Factor VM, Thorgeirsson SS. Activation of the canonical Wnt $/ \beta$ catenin pathway confers growth advantages in c-Myc/ E2F1 transgenic mouse model of liver cancer. Journal of Hepatology. 2005; 42:842-849.

24. Cieply B, Zeng G, Proverbs-Singh T, Geller DA, Monga SPS. Unique phenotype of hepatocellular cancers with exon-3 mutations in beta-catenin gene. Hepatology. 2008; 49:821-831.

25. Calvisi DF, Factor VM, Loi R, Thorgeirsson SS. Activation of beta-catenin during hepatocarcinogenesis in transgenic mouse models: relationship to phenotype and tumor grade. Cancer research. 2001; 61:2085-2091.

26. Guichard C, Amaddeo G, Imbeaud S, Ladeiro Y, Pelletier L, Maad IB, Calderaro J, Bioulac-Sage P, Letexier M, Degos F, Clément B, Balabaud C, Chevet E, et al. Integrated analysis of somatic mutations and focal copy-number changes identifies key genes and pathways in hepatocellular carcinoma. Nature Genetics. 2012; 44:694-698.

27. Monga SP. beta-Catenin Signaling and Roles in Liver Homeostasis, Injury, and Tumorigenesis. Gastroenterology. 2015; 148:1294-1310.

28. Harada N, Miyoshi H, Murai N, Oshima H, Tamai Y, Oshima M, Taketo MM. Lack of tumorigenesis in the mouse liver after adenovirus-mediated expression of a dominant stable mutant of beta-catenin. Cancer research. 2002; 62:1971-1977.

29. Harada N, Oshima H, Katoh M, Tamai Y, Oshima M, Taketo MM. Hepatocarcinogenesis in mice with betacatenin and Ha-ras gene mutations. Cancer research. 2004; 64:48-54.

30. Zhang XF, Tan X, Zeng G, Misse A, Singh S, Kim Y, Klaunig JE, Monga SPS. Conditional $\beta$-catenin loss in mice promotes chemical hepatocarcinogenesis: Role of oxidative stress and platelet-derived growth factor receptor $\alpha /$ phosphoinositide 3-kinase signaling. Hepatology. 2010; 52:954-965.

31. Halilbasic E, Claudel T, Trauner M. Bile acid transporters and regulatory nuclear receptors in the liver and beyond. J Hepatol. 2013; 58:155-168.

32. Kuipers F, Bloks VW, Groen AK. Beyond intestinal soap-bile acids in metabolic control. Nature reviews Endocrinology. 2014; 10:488-498.

33. Schaap FG, Trauner M, Jansen PL. Bile acid receptors as targets for drug development. Nature reviews Gastroenterology \& hepatology. 2014; 11:55-67.

34. Thomas C, Pellicciari R, Pruzanski M, Auwerx J, Schoonjans K. Targeting bile-acid signalling for metabolic diseases. Nature reviews Drug discovery. 2008; 7:678-693.

35. Chiang JY. Bile acids: regulation of synthesis. Journal of lipid research. 2009; 50:1955-1966.

36. Weisend CM, Kundert JA, Suvorova ES, Prigge JR, Schmidt EE. Cre activity in fetal albCre mouse hepatocytes: Utility for developmental studies. Genesis. 2009; 47:789-792.

37. Zulehner G, Mikula M, Schneller D, van Zijl F, Huber H, Sieghart W, Grasl-Kraupp B, Waldhor T, PeckRadosavljevic M, Beug H, Mikulits W. Nuclear betacatenin induces an early liver progenitor phenotype in hepatocellular carcinoma and promotes tumor recurrence. Am J Pathol. 2010; 176:472-481.

38. Audard V, Grimber G, Elie C, Radenen B, Audebourg A, Letourneur F, Soubrane O, Vacher-Lavenu MC, Perret C, Cavard C, Terris B. Cholestasis is a marker for hepatocellular carcinomas displaying beta-catenin mutations. The Journal of pathology. 2007; 212:345-352. 
39. Colnot S, Decaens T, Niwa-Kawakita M, Godard C, Hamard G, Kahn A, Giovannini M, Perret C. Liver-targeted disruption of Apc in mice activates beta-catenin signaling and leads to hepatocellular carcinomas. Proceedings of the National Academy of Sciences of the United States of America. 2004; 101:17216-17221.

40. Loeppen S, Koehle C, Buchmann A, Schwarz M. A beta-catenin-dependent pathway regulates expression of cytochrome P450 isoforms in mouse liver tumors. Carcinogenesis. 2005; 26:239-248.

41. Liu X, Zhang X, Ji L, Gu J, Zhou M, Chen S. Farnesoid X receptor associates with beta-catenin and inhibits its activity in hepatocellular carcinoma. Oncotarget. 2015; 6:4226-4238. doi: 10.18632/oncotarget.2899.

42. Postic C, Magnuson MA. DNA excision in liver by an albumin-Cre transgene occurs progressively with age. Genesis. 2000; 26:149-150.

43. Harada N, Tamai Y, Ishikawa T, Sauer B, Takaku K, Oshima M, Taketo MM. Intestinal polyposis in mice with a dominant stable mutation of the beta-catenin gene. The EMBO Journal. 1999; 18:5931-5942.

44. Schuler M, Dierich Ae, Chambon P, Metzger D. Efficient temporally controlled targeted somatic mutagenesis in hepatocytes of the mouse. Genesis. 2004; 39:167-172.

45. Fuchs CD, Claudel T, Kumari P, Haemmerle G, Pollheimer MJ, Stojakovic T, Scharnagl H, Halilbasic E, Gumhold J, Silbert D, Koefeler H, Trauner M. Absence of adipose triglyceride lipase protects from hepatic endoplasmic reticulum stress in mice. Hepatology. 2012; 56:270-280.

46. Jha P, Claudel T, Baghdasaryan A, Mueller M, Halilbasic E, Das SK, Lass A, Zimmermann R, Zechner R, Hoefler G, Trauner M. Role of adipose triglyceride lipase (PNPLA2) in protection from hepatic inflammation in mouse models of steatohepatitis and endotoxemia. Hepatology. 2014; 59:858-869.

47. Osterreicher CH, Taura K, De Minicis S, Seki E, PenzOsterreicher M, Kodama Y, Kluwe J, Schuster M, Oudit GY, Penninger JM, Brenner DA. Angiotensin-convertingenzyme 2 inhibits liver fibrosis in mice. Hepatology. 2009; 50:929-938.

48. Osterreicher CH, Penz-Osterreicher M, Grivennikov SI, Guma M, Koltsova EK, Datz C, Sasik R, Hardiman G, Karin M, Brenner DA. Fibroblast-specific protein 1 identifies an inflammatory subpopulation of macrophages in the liver. Proc Natl Acad Sci USA. 2011; 108:308-313.

49. Fickert P, Zollner G, Fuchsbichler A, Stumptner C, Pojer C, Zenz R, Lammert F, Stieger B, Meier PJ, Zatloukal K, Denk H, Trauner M. Effects of ursodeoxycholic and cholic acid feeding on hepatocellular transporter expression in mouse liver. Gastroenterology. 2001; 121:170-183.

50. Fickert P, Wagner M, Marschall HU, Fuchsbichler A, Zollner G, Tsybrovskyy O, Zatloukal K, Liu J, Waalkes MP, Cover C, Denk H, Hofmann AF, Jaeschke H, et al. 24-norUrsodeoxycholic acid is superior to ursodeoxycholic acid in the treatment of sclerosing cholangitis in Mdr2 (Abcb4) knockout mice. Gastroenterology. 2006; 130:465-481.

51. Tremaroli V, Karlsson F, Werling M, Stahlman M, Kovatcheva-Datchary P, Olbers T, Fandriks L, le Roux CW, Nielsen J, Backhed F. Roux-en-Y Gastric Bypass and Vertical Banded Gastroplasty Induce Long-Term Changes on the Human Gut Microbiome Contributing to Fat Mass Regulation. Cell metabolism. 2015; 22:228-238. 